\title{
The study of structural fields of daily gas consumption of the balance groups of the regional gas supply system
}

\author{
Deniz Moroz ${ }^{1}$, Nadzeya Hruntovich $^{2}$, Nikolay Hruntovich ${ }^{2}$, Svetlana Jhukovets ${ }^{2}$, Aleksey Kapansky ${ }^{2}$, and Leonid \\ Dolomanyak $^{3}$
}

${ }^{1}$ State Enterprise "Research Institute Belgiprotopgaz", Domashevskij lane,11a, Minsk, Republic of Belarus

${ }^{2}$ Sukhoi State Technical University of Gomel, Prospect Octiabria, 48, 246746, Gomel, Republic of Belarus

${ }^{3}$ Kazan State Power Engineering University, str. Krasnoselskaya, 51, 420066, Kazan, Russia

\begin{abstract}
The study of the balance sheet structure of the regional gas supply system is necessary to solve a number of operational tasks. An information database has been created for conducting research. It includes information on daily gas consumption and the actual average daily outdoor temperature for a six-year period for more than 539 elements of the balance structure of the regional gas supply system. The most significant factors determining gas consumption were identified for 7 enlarged balance groups. It's investigated the dynamics of factors in time. The article presents the types of daily fields "gas flow - average daily outdoor temperature" for enlarged groups of the balance structure of the regional gas supply system. Four temperature areas were identified and substantiated in the daily fields. The assessment of qualitative and quantitative indicators characterizing the temperature areas is presented in the article.
\end{abstract}

\section{Introduction}

A systematic approach to the study of properties, patterns of development and functioning of energy objects in the 60 s of the last century was laid by academician L. A. Melentyev and continued its development in the works of his students and followers around the world $[1,2]$. A systematic approach involves a comprehensive review of the system, taking into account its external and internal relationships, all possible research purposes or management criteria, various restrictions and consequences of decisions. The meaning and content of the system approach proposed by academician L. A. Melentyev for energy systems, which includes the gas supply system, is clarified by the allocation of four components [3, 4]: the study and accounting of external relations of the system under consideration; a hierarchical view of the internal structure of complex objects and their management processes; accounting for uncertainties caused by incomplete source information, multicriteria and other factors; the use of mathematical modeling methods and information and computing tools to describe the object under study [5, 6, 7, 8]. Effective management of the modern regional gas supply system (RGS) should be based and developed on the principles of the system analysis, which primarily involves the study of the properties, patterns of functioning of enlarged balance groups and the gas supply system as a whole $[9,10,11$, 12]. For these purposes, it is proposed to use the structural fields of daily gas consumption from the average daily outdoor temperature (Bday-tday) and a system of indicators that characterize temperature zones over an annual time interval. The conducted research allowed us to form approaches to the construction of structural fields, which consist in rationing the daily values of gas consumption for all enlarged groups of the balance structure relative to the average annual values. The average daily outdoor temperature was converted to Kelvin degrees and correlated with the average annual values, which made it possible to exclude negative temperatures and further compare both types of structural fields and their characteristics for different years, both for the balance group and between different enlarged balance groups.

\section{Research results}

The enlarged balance structure of gas consumption for the studied RGS can be represented by seven groups: «Energetics», «Agriculture and cooperation», «Municipal, population», «Ministry of housing and communal services», «Industry», «Other non-industrial purposes», «Other no affiliation». The contribution of each enlarged group to the total gas consumption of the region is shown in figure 1 . The largest gas consumption is accounted for the group «Energetics» - 50.2\%, «Industry» - 22.6\%, «Municipal, population» - 13.2\%, «Ministry of housing and communal services». The «Industry» group includes 6 subgroups of various departmental affiliation, and in total, the «Industry» group includes 106 balance elements - industrial enterprises [1, 2]. 
To construct the structural fields « $B_{d a y}-t_{d a y} »$, an information database was created for 2012-2017, containing information on daily gas consumption and average daily outdoor temperature for 539 elements of

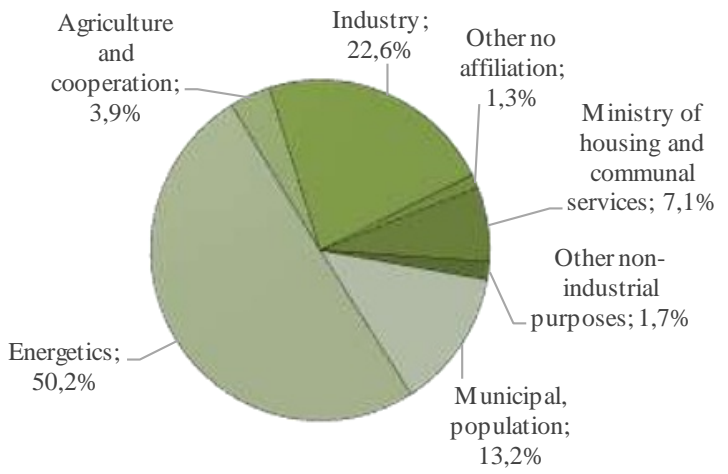

Fig. 1. Structure of gas consumption by enlarged groups RGS.

An assessment of the degree of closeness of the relationship between the $\left\langle B_{d a y}-t_{d a y}\right\rangle$ for the enlarged balance groups and the RGS as a whole was made (table 1). The most stable and high degree of closeness of the relationship between the average daily temperature and daily gas consumption has the RGS as a whole: $\mathrm{R}\left(t_{d a y}-B_{d a y}\right)$ is in the range $-0.92 \div-0.94$. The RGS shows properties characteristic of large technical systems: inertia and emergence [3, 4]. A high correlation coefficient $R\left(t_{\text {day }}-B_{\text {day }}\right)$ is observed among the groups «Energetics», «Ministry of housing and communal services», «Municipal, population», which is mainly associated with the operation of the heating system. The «Industry» group has the lowest correlation coefficient $R=-0.46 \div-0.64$, which indicates the need to search for and justify additional factors that determine the gas consumption of end consumers.

Table 1. Results of the assessment of the degree of closeness of the relationship between daily gas consumption and outdoor temperature for the enlarged balance groups of the RGS for 2012-2017.

\begin{tabular}{|c|c|c|c|c|c|c|}
\hline \multirow{2}{*}{$\begin{array}{l}\text { Enlarged groups of } \\
\text { the balance } \\
\text { structure of the RGS }\end{array}$} & \multicolumn{6}{|c|}{$\begin{array}{c}\text { Correlation coefficients between the average } \\
\text { daily outdoor temperature and daily gas } \\
\text { consumption, } \\
R\left(t_{d a v}-B_{d a v}\right)\end{array}$} \\
\hline & $\stackrel{\text { ก }}{\stackrel{2}{*}}$ & $\stackrel{m}{\stackrel{n}{\sim}}$ & $\stackrel{\Delta}{\stackrel{\sim}{*}}$ & $\frac{n}{2}$ & $\stackrel{\circ}{\stackrel{0}{*}}$ & 홍 \\
\hline $\begin{array}{l}\text { Submission (RGS in } \\
\text { general), including: }\end{array}$ & -0.94 & -0.92 & -0.93 & -0.92 & -0.94 & -0.94 \\
\hline $\begin{array}{l}\text { Group «Municipal, } \\
\text { population» }\end{array}$ & -0.93 & -0.94 & -0.87 & -0.89 & -0.92 & -0.91 \\
\hline Group «Energetics» & -0.93 & -0.94 & -0.68 & -0.91 & -0.92 & -0.91 \\
\hline Group «Industry» & -0.80 & -0.59 & -0.61 & -0.53 & -0.52 & -0.49 \\
\hline $\begin{array}{c}\text { Group «Other non- } \\
\text { industrial purposes» }\end{array}$ & -0.61 & -0.59 & -0.51 & -0.46 & -0.63 & -0.64 \\
\hline $\begin{array}{l}\text { Group «Agriculture } \\
\text { and cooperation» }\end{array}$ & -0.84 & -0.78 & -0.87 & -0.71 & -0.80 & -0.66 \\
\hline $\begin{array}{l}\text { Group «Other no } \\
\text { affiliation» }\end{array}$ & -0.85 & -0.88 & -0.79 & -0.58 & -0.85 & -0.82 \\
\hline $\begin{array}{l}\text { Group «Ministry of } \\
\text { housing and } \\
\text { communal services» }\end{array}$ & -0.96 & -0.95 & -0.92 & -0.92 & -0.93 & -0.93 \\
\hline
\end{tabular}

Structural fields for 2012-2017 were constructed for the enlarged balance groups and for the RGS as a whole and their type was determined (figure 2). There are two main types of $\left.« B_{d a y}-t_{d a y}\right\rangle$ fields:

a) a field with a clear separation into two temperature regions, determined by the state of the heating system («on» or «off») and the overlap of these areas in the zone of unstable, uncertain state of the RGS (from $0^{\circ} \mathrm{C}$ to $13.6^{\circ} \mathrm{C}$ ). This type of field is characteristic for RGS and for the following groups «Municipal, population», «Energetics», «Ministry of housing and communal services».

b) a field without a pronounced delamination into temperature regions, with a dependence of the growth of daily gas consumption when the outdoor temperature decreases with a significant vertical spread of $B_{d a y}$ at the same value of the outdoor temperature. This type of field is typical for such groups as «Other non-industrial purposes», «Agriculture, cooperation», «Other no affiliation», «Industry».

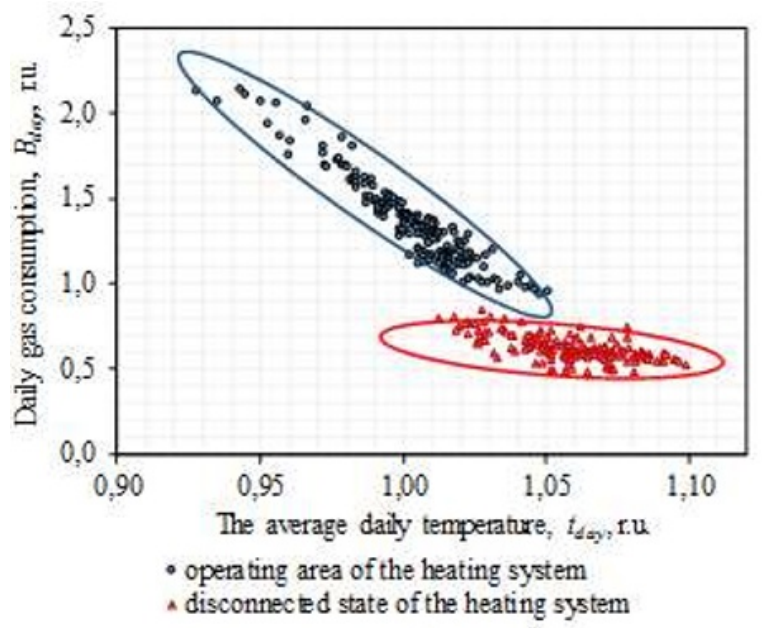

a)

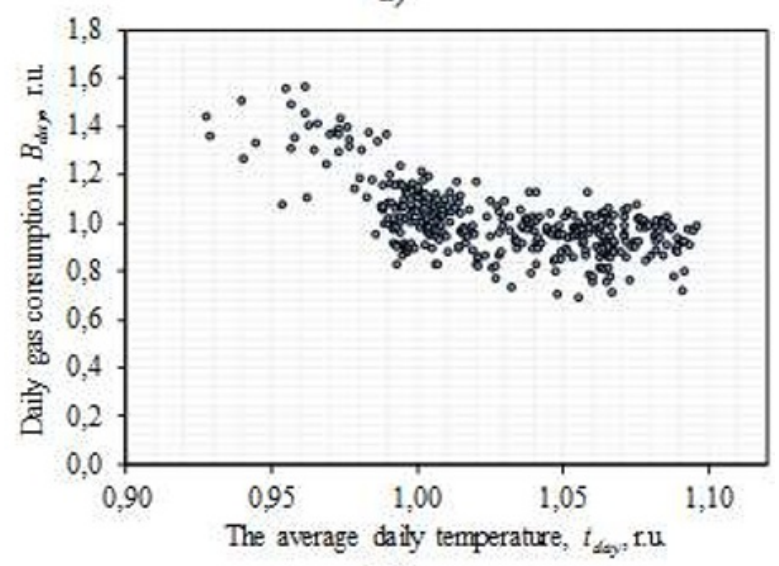

b)

Fig. 2. The main types of structural fields $\left\langle B_{d a y}-t_{d a y} »\right.$.

Four temperature ranges are proposed for the analysis of the structural fields $\left." B_{d a y}-t_{d a y}\right\rangle$ (figure 3): first temperature range $0,9 \div 0,97 \mathrm{r}$.u. that corresponds to the range of daily average temperature from $-27,3{ }^{\circ} \mathrm{C}$ to $-8,2^{\circ} \mathrm{C}$; the second temperature range $0,97 \div 1$ r.u. that corresponds to the range of daily average temperature from $-8,2{ }^{\circ} \mathrm{C}$ to $0{ }^{\circ} \mathrm{C}$; the third temperature range 
$1.0 \div 1.05$ r.u., that corresponds to the range of daily average temperature from $0^{\circ} \mathrm{C}$ to $+13,6^{\circ} \mathrm{C}$; a fourth temperature range is more than 1.05 r.u., that corresponds to an average daily temperature of more than $+13,6^{\circ} \mathrm{C}$.

The choice of average daily temperature ranges is due to several reasons:

- the first and second temperature range refers to the winter period with stable values of negative temperature, which implies that the heating system is switched on. The allocation of the second temperature range $t_{d a y}=0.97 \div 1$ for the winter period is due to the fact that it includes up to $60 \%$ of the day of the heating period;

- the third range $t_{d a y}=1 \div 1.05$ is selected separately for analysis, because in this range the greatest uncertainty appears in the modes of operation of the RGS. In this range two states of the heating system are possible: «enabled» and «disabled». This range includes the days of March, April, and October;

- the fourth range $t_{d a y}>1.05$ combines a day with a stable positive temperature value and a disabled state of the heating system.

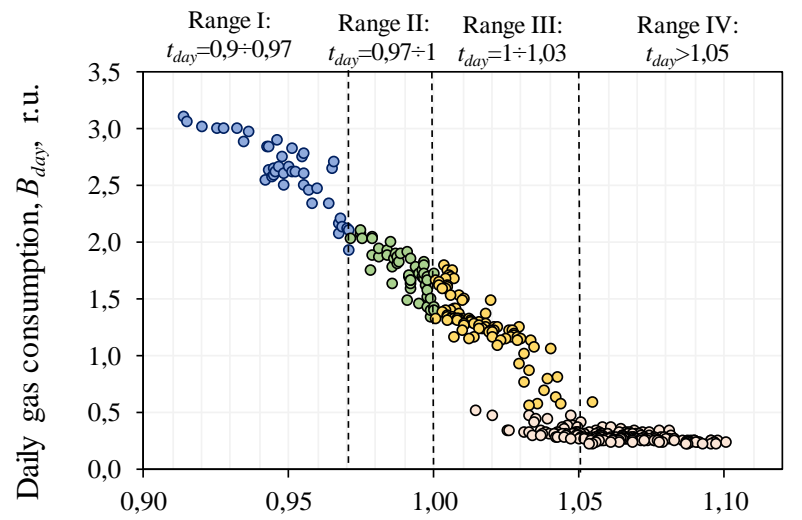

The average daily temperature, $t_{d a y}$, r.u.

Fig. 3. Temperature ranges for the analysis of the structural fields « $\left.B_{d a y}-t_{d a y}\right\rangle$.

Structural fields $\left\langle B_{d a y}-t_{d a y}\right\rangle$ were evaluated by the following parameters: change in outdoor temperature, $t_{\text {day }}$, expressed in absolute $\left({ }^{\circ} \mathrm{C}\right)$ and relative (r.u.) units; average daily gas consumption in the temperature range,

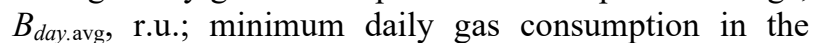
temperature range, $B_{d a y \text { min, }}$ r.u.; maximum daily gas consumption in the temperature range, $B_{\text {day.max }}$, r.u.; number of days in the temperature range, $N$, day; standard deviation of gas consumption in the range, $\sigma$, r.u.; coefficient of variation for gas in the temperature range, $V, \%$; relative change in temperature in the range, $\Delta t$, r.u.; sensitivity coefficient of relative change in gas consumption $\Delta \mathrm{B}$ with a relative change in outdoor temperature $\Delta t, K_{s}$, r.u.

The greatest interest for research is $K_{s}$, which is calculated as the ratio of the difference between the maximum and minimum gas consumption $\Delta \mathrm{B}$ in the range to the difference between the maximum and minimum outdoor temperature $\Delta t$ :

$$
K_{s}=\frac{\left(B_{d a y \text { max }}-B_{\text {day.min }}\right)}{\left(t_{\text {day.max }}-t_{\text {day.min }}\right)}=\frac{\Delta B}{\Delta t} .
$$

Table 2 shows the average $K_{s}$ values for 2012-2017.

Table 2. Results of assessing the degree of closeness of the relationship between daily gas consumption and outdoor temperature for the enlarged balance groups of the RGS for 2012-2017.

\begin{tabular}{|c|c|c|c|c|}
\hline \multirow{2}{*}{$\begin{array}{l}\text { Large balance } \\
\text { group }\end{array}$} & \multicolumn{4}{|c|}{$\begin{array}{l}\text { Sensitivity coefficient, } K_{\text {savg }} 2012 \div 2017 \text { y. over the } \\
\text { ranges } t_{d a v} \text {, r.u. }\end{array}$} \\
\hline & $\begin{array}{c}\text { Range I } \\
t_{\text {day }}=0,9 \div 0,97\end{array}$ & \begin{tabular}{|c} 
Range II \\
$t_{\text {day }}=0,97 \div 1$
\end{tabular} & $\begin{array}{c}\text { Range III } \\
t_{\mathrm{day}}=1 \div 1,05\end{array}$ & $\begin{array}{l}\text { Range IV } \\
t_{\text {day }}>1,05\end{array}$ \\
\hline RGS & 7,01 & 19,66 & 26,36 & 9,73 \\
\hline $\begin{array}{l}\text { «Municipal, } \\
\text { population» }\end{array}$ & 10,08 & 26,24 & 42,37 & 12,90 \\
\hline «Industry» & 4,60 & 14,74 & 15,87 & 6,10 \\
\hline $\begin{array}{l}\text { «Other no } \\
\text { affiliation» }\end{array}$ & 7,82 & 21,69 & 27,27 & 9,05 \\
\hline $\begin{array}{l}\text { «Agriculture and } \\
\text { cooperation» }\end{array}$ & 9,05 & 26,73 & 27,33 & 10,37 \\
\hline $\begin{array}{l}\text { «Other non- } \\
\text { industrial } \\
\text { purposes» }\end{array}$ & 9,07 & 25,50 & 36,32 & 13,75 \\
\hline «Energetics» & 8,74 & 25,80 & 37,79 & 12,97 \\
\hline $\begin{array}{l}\text { «Ministry of } \\
\text { housing and } \\
\text { communal } \\
\text { services» }\end{array}$ & 12,22 & 30,90 & 54,56 & 14,39 \\
\hline
\end{tabular}

Evaluation of indicators that characterize the structural fields $\left\langle B_{d a y}-t_{d a y}\right\rangle$ :

- the first range corresponding to the lowest outdoor temperature includes the least number of days in the annual time interval. In 2015, this range included 7 days, and in $2012-42$ days. This range has a lower sensitivity coefficient for all groups: $K_{\mathrm{s}}, \mathrm{I}<<\mathrm{Ks}$, II $<<\mathrm{Ks}$, III. This indicates a decrease in the influence of regulation in heating systems and the reached limit values of heating loads;

- the second range with a temperature $t_{\text {day }}=0.97 \div 1$ or from $-8.2^{\circ} \mathrm{C}$ to $0^{\circ} \mathrm{C}$ has a higher $K_{s}$ compared to the first and fourth regions, which indicates the regulatory ability to consume gas in the RGS;

- the third range with the temperature $t_{\text {day }}=1 \div 1.05$ (from 0 to $13.6^{\circ} \mathrm{C}$ ) is unstable in terms of modes for such groups as «Municipal, population» and «Ministry of housing and communal services», the RGS as a whole, since the state of the heating system is ambiguous in this range. The Ks for this range is several times higher than the $K_{\mathrm{s}}$ of the fourth and first ranges. In this range the daily field of the $B_{\text {day }}$ is divided into two areas with low gas consumption (the heating system is not included) and with a high 1.5 to 2 fold increase in the average daily gas consumption (the heating system is switched on)

- the fourth range, corresponding to the highest outdoor temperature, combines from $53 \%$ to $46 \%$ of the number of days of their annual value. For this range, the sensitivity coefficient of the $K_{s}$ is several times less than $K_{s}$ of the third and second ranges: $K_{s}, \mathrm{IV}<<\mathrm{Ks}, \mathrm{II}<<$ $K_{s}$, III.

It should be noted that for the «Industry» group, the fourth and the third range $K_{s}$ are the lowest of all 
enlarged RGS groups, which indicates a lower degree of influence of outdoor temperature. The daily gas consumption regimes of the «Industry» group are formed at the expense of technological consumption for output.

\section{Conclusions}

For 7 enlarged balance groups and RGS as a whole the field types are defined as $\left\langle B_{d a y}-t_{d a y}\right\rangle$ : a field with a clear stratification into two temperature regions, defined by the condition of the heating system (enabled or disabled) and the overlap of these areas in the area of the unstable state of RGS; field without a pronounced stratification into temperature regions, with a dependence of the growth of daily gas consumption with a decrease in the temperature of the outdoor air with a significant vertical dispersion of $B_{d a y}$ when the outdoor temperature is the same. 4 temperature ranges and a system of indicators for analyzing gas consumption modes are proposed. The proposed $K_{s}$ allows us to evaluate the gas regulation capacity in each temperature range, as well as to evaluate individual features of gas supply modes for enlarged balance groups.

\section{References}

[1] L. Melentiev, Selected works, Methodology of system researches in power engineering (Moscow, Nauka, 289, 1995)

[2] Ed. N. Voropay, System research in the energy sector: retrospective of scientific directions of the SEI - ISEM (Novosibirsk, Nauka, 686, 2010)

[3] N. Ilkevich, Multilevel modeling of the development of gas supply systems (Novosibirsk, Nauka, 217, 2014)

[4] N. Ilkevich, T. Dzyubina, Zh. Kalinina, S. Okuneva, Simulation of the equilibrium of the flows of the cost of supply and demand on natural gas, Pipeline systems of power engineering: methodical and applied problems of mathematical modeling (Novosibirsk, Nauka, 318-331, 2015)

[5] M. Shevchenko, Development of private models for monitoring the regional gas supply system. Technological audit and production reserves $\mathbf{6}, 2$ (26), 40-46 (2015)

[6] G. Galustov, S. Brovchenko, S. Meleshkin, Mathematical modeling and forecasting in technical systems: Educational (Taganrog, Publishing house of TTI JUFU, 30, 2008)

[7] F. Peregudov, Introduction to system analysis (Moscow, Vysshaja shkola. 367, 1989)

[8] N.V. Hruntovich, A.A. Kapanski, D. Baczynski, G.V. Vagapov, O.V. Fedorov, Optimization of a variable frequency drive pump working on a water tower, EDP Sciences, E3S Web of Conferences 124, 05060 (2019)

[9] O.V. Fedorov, Expeditious forecasting of power consumption, 2017 International Conference on Industrial Engineering, Applications and Manufacturing (ICIEAM), IEEE (2017)
[10] Y.I. Gracheva, O.V. Naumov, Estimation of Power Losses in Electric Devices of the Electrotechnical Complex, International Conference on Industrial Engineering, Applications and Manufacturing, ICIEAM, 6 (2019)

[11] A.A. Shpiganovich, K.A. Pushnitsa, E.V. Churkina, O.V. Fedorov, Features of the operation of power supply systems of ferrous metallurgy enterprises, Ferrous metals 5, 56-61 (2017)

[12] Y.I. Gracheva, A.N. Alimova, Calculating Methods and Comparative Analysis of Losses of Active and Electric Energy in Low Voltage Devices, International Ural Conference on Electrical Power Engineering (UralCon), 361367 (2019)

[13] N. Gruntovich, D. Moroz, V. Shalonik, About necessity of study the structure and regularities of the functioning of regional gas supply systems, Energeticheskaja strategija, 1, 42-46 (2017)

[14] D. Moroz, A. Kapanskij, Development of models of gas consumption by structural elements of the regional gas supply system, Energy saving and efficiency in technical systems, Materials of the IV International Scientific and Technical Conference of Students, Young Scientists and Specialists, Tambov State Technical University, 416-418 (2017)

[15] D.R. Moroz, N.V. Hruntovich, Regional Gas Supply System Considered from the Standpoint of System Analysis and Regularities of its Functioning. Energetika, Proc. CIS Higher Educ. Inst. and Power Eng. Assoc. 61, 4, 359-371. DOI: 10.21122/1029-7448-2018-61-4-359-371 (2018)

[16] R. Kantjukov, M. Sukharev, V. Meshalkin, R. Gimranov, A. Popov, I. Ryzhenkov, Forecast gas consumption - the basis for making rational decisions on the structure and technological parameters in the design and reconstruction of the gas supply system, Electronic scientific journal Oil and Gas Business 1, 201-221 (2015) 